\title{
Strategies for pricing of pharmaceuticals and generics in developing countries
}

(Commentary for GaBI Journal)

Brian Godman ${ }^{1,2,3}$, BSc, PhD, Mohamed Azmi Hassali4 PhD

${ }^{1}$ Strathclyde Institute of Pharmacy and Biomedical Sciences, University of Strathclyde, Glasgow, United Kingdom. Email: Brian.godman@strath.ac.uk

2Department of Laboratory Medicine, Division of Clinical Pharmacology, Karolinskalnstitutet, Karolinska University Hospital Huddinge, Stockholm, Sweden. Email: Brian.Godman@ki.se

${ }^{3}$ Health Economics Centre, University of Liverpool Management School, Liverpool, UK. ${ }^{4}$ Discipline of Social and Administrative Pharmacy, School of Pharmaceutical Sciences, Universiti Sains Malaysia, Penang, Malaysia. Email: azmihassali@usm.com

${ }^{*}$ Author for correspondence: Strathclyde Institute of Pharmacy and Biomedical Sciences, University of Strathclyde, Glasgow G4 0RE, United Kingdom. Email: Brian.godman@strath.ac.uk. Telephone: 0141548 3825. Fax: 01415522562 and Division of Clinical Pharmacology, Karolinska Institute, Karolinska University Hospital Huddinge, SE-141 86, Stockholm, Sweden. Email:

Brian.Godman@ki.se. Telephone + 46858581068 . Fax + 46859581070

Dr Brian Godman and Professor Mohamed Azmi Hassali review Rida et al regarding pricing strategies for pharmaceuticals in developing countries.

Rida and Ibrahim are to be congratulated on their extensive review of ongoing pricing strategies in developing countries (1), also referred to as lower and middle income countries (LMICs). These include advocating policies regarding mark-ups for pharmaceuticals, pricing formulae for medicines, external reference pricing, as well as encouraging greater use of generics (2-4). However, there are concerns over external reference pricing (ERP), especially for new medicines where pharmaceutical companies are potentially delaying launch or not launching in some countries to maintain high prices (5). There are also concerns over the ability to rapidly obtain low prices for generics if prices under ERP systems are only reviewed annually or biannually. Aggressive pricing policies in the Netherlands, including 3-monthly tendering, led to prices of generic omeprazole and simvastatin dropping to just $2 \%$ of the originator price in a short time period (6). In Sweden, compulsory generic substitution with the lowest priced generic also led to rapid price erosion following generic availability. Prices fell further following the instigation of monthly auctions where the cheapest generic was guaranteed a substantial proportion of the market the following month $(7,8)$.

The prices of pharmaceuticals are a particular issue in LMICs, where medicines can account for up to $60 \%$ of total healthcare expenditures, and where up to $90 \%$ of the population purchase medicines through co-payments $(9,10)$. High co-payments impact on adherence of non-communicable diseases (NCDs) as well as on access to biologicals to treat immunological diseases (11-13). This is a concern with NCDs as for example, currently 3 out of 4 patients with hypertension live in LMICs (14). As mentioned by Rida and Ibrahim, promoting generics is a major way to reduce prices and enhance access to appropriate medicines $(1,10,15,16)$. Although things are changing $(10,16)$, to date there have only been a limited number There are also a comparative lack of strategies in place to combat the activities of pharmaceutical companies who are promoting their branded medicines and negatively impacting on the use of generics (17). The lack of promotion of generics can often be coupled with a lack of formal pricing strategies for generics (8). This can be a major concern for countries and patients treating NCDs as generics for NCDs can be manufactured and distributed for as little as US\$1/ patient/ month $(18,19)$.

The lack of formal pricing strategies in place for generics in LMICs contrasts sharply with European countries where there are multiple formal pricing policies. These can be collated under three main themes $(10,20,21)$ and include (8): regulated systems (prescriptive pricing) where there are established rules for the pricing of generics, as seen in Belgium, Croatia, France, Hungary, Norway and Poland; free pricing - where manufacturers are (relatively) free to set prices of generics, as seen in Germany, Netherlands, Sweden and the UK; however, typically there are programmes in place to obtain low prices; or a mixed approach - which is a combination of the two different approaches, as currently seen in Austria (10, 22-25). 
As a result of the different pricing policies, there can be substantial price differences for generics $(8$, $21,26)$. Overall, generic prices can vary by up to 36 fold across countries depending on the pricing policies (27), with prices generally lower in countries with higher consumption of generics (28). This is independent of the size of the country $(29,30)$. Different countries across Europe and other parts of the world have also used a variety of other approaches to promote the use of generics. These include educational approaches, financial incentives and laws. Laws include compulsory generic substitution, as seen in Sweden, or compulsory INN prescribing, as seen in Lithuania $(7,29)$.

Despite the efforts being made, there are still a number of barriers that need to be addressed to enhance the prescribing and dispensing of generics, especially in LMICs $(10,31,32)$. These include addressing fears associated with generic substitution that are enhanced by concerns over the efficacy and safety of generics $(33,34)$. Such fears resulted in Hassali et al. developing a list of requirements that should be met to enhance successful substitution (35). Education needs include encouraging high international nonproprietary name (INN) prescribing which is advocated by the WHO for noncontroversial products, as seen in Scotland where rates are close to the $100 \%(8,36)$. Financial incentives include greater patient co-payments for branded products of the same molecule, which is typically practiced across Europe (21). Potential initiatives can also include reducing financial disincentives to the prescribing of generics, as currently seen in China. Here, both hospitals and physicians need to prescribe branded products with associated procured discounts to enhance their incomes (37). This is in addition to the measures mentioned by Rida and Ibrahim in their Table (Table 1) (1).

It is important that appropriate care is taken when introducing pricing policies for generics. In 2012, the South Korean government set the same maximum reimbursement price for originators and generics in an attempt to make the market more competitive, building on earlier reforms mentioned by Rida and Ibrahim (Table 1) (38). However, given the concerns that still exist among physicians in Korea regarding generics, the opposite was achieved. The price dispersion between different generics significantly decreased and originator utilization significantly increased (38). A similar situation was seen when compulsory INN prescribing was introduced. Implementation of this policy in Abu Dhabi, UAE, did not achieve the desired results as physicians were not incentivised to preferentially prescribe the generic medicines and pharmacists' remuneration was not altered to preferentially dispense the cheapest INN product (39).

Many countries have also implemented a variety of approaches to the pricing and reimbursement of new medicines. Whilst all countries use critical appraisal techniques to assess the level of health gain with new medicines as part of pricing negotiations, some countries use this as a basis for pricing negotiations, e.g. Austria, France and Germany. Othersuse this information to develop economic parameters, such as the extent of an increase in quality adjusted life years with the new medicine with or without a budget impact analysis (QALYs) (40-42). One concern is that most countries that utilise QALYs do not set thresholds, which can be exploited by pharmaceutical companies, especially in emotive disease areas such as cancer and orphan diseases $(40,43,44)$.

There is also growing use of risk sharing arrangements brought about by the ever increasing prices of new medicines and issues of affordability in European countries $(41,45,46)$. This contrasts sharply with LMIC countries where currently there are few formal pricing approaches for new medicines, as discussed by Rida and Ibrahim (1). Examples of pricing strategies that could be considered by LMICs when funding new medicines include those currently instigated in Austria $(41,47)$. This is in addition to ERP as advocated by the WHO (4). In Austria, new medicines that are similar to existing standards are expected to be priced lower than the current standard prices for reimbursement (48). New medicines that have added benefit can potentially command up to $10 \%$ more than the current standard prices, with prices for new medicines that are deemed to have substantially more added value, being allowed to have prices similar to comparable European countries endorsed by health economic evaluations (48). In the case of LMICs, this would mean prices similar to other LMICs with similar economic situations, as seen in Europe (3). With only a few new medicines typically seen as innovative, this means that most new medicines will be priced below or just above current standards $(41,47)$, greatly increasing affordability and access.

In conclusion, Rida and Ibrahim's research has been extensive. They have highlighted the need for LMICs to develop suitable pricing strategies for medicines to enhance access to affordable medicines. This is essential, given rising rates of NCDs and other diseases. There is an opportunity for LMICs to 
learn from other countries, such as those in Europe who are developing strategies to cope with growing resource pressures on healthcare systems and the need to maintain equitable and comprehensive healthcare for all $(8,41)$.

\section{Conflicts of interest}

Neither author has any conflicts of interest to declare.

\section{References}

1. Rida NMA, Ibrahim M. Pricing strategies for pharmaceuticals in developing countries: what option do we have? Generics and Biosimilar Journal. 2017;6(1):1-3.

2. Putrik P, Ramiro S, Kvien TK, Sokka T, Pavlova M, Uhlig T, et al. Inequities in access to biologic and synthetic DMARDs across 46 European countries. Annals of the rheumatic diseases. 2014;73(1):198-206.

3. Leopold C, Vogler S, Mantel-Teeuwisse AK, de Joncheere K, Leufkens HG, Laing R. Differences in external price referencing in Europe: a descriptive overview. Health policy. 2012;104(1):50-60.

4. WHO. WHO Guideline on Country Pharmaceutical Pricing Policies. Available at URL: http://apps.who.int/medicinedocs/documents/s21016en/s21016en.pdf

5. Carone G, Schwierz C, Xavier A. Cost-containment policies in public pharmaceutical spending in the EU. Available at URL:

http://ec.europa.eu/economy finance/publications/economic paper/2012/pdf/ecp 461 en.pdf 6. Woerkom M, Piepenbrink H, Godman B, Metz J, Campbell S, Bennie M, et al. Ongoing measures to enhance the efficiency of prescribing of proton pump inhibitors and statins in The Netherlands: influence and future implications. Journal of comparative effectiveness research. 2012;1(6):527-38

7. Godman B, Wettermark B, Hoffmann M, Andersson K, Haycox A, Gustafsson LL. Multifaceted national and regional drug reforms and initiatives in ambulatory care in Sweden: global relevance. Expert review of pharmacoeconomics \& outcomes research. 2009;9(1):65-83.

8. Godman B, Baker A, Leporowski A, Morton A, Baumgärtel C, Bochenek T, Fadare J et al. Initiatives to increase the prescribing of low cost generics; the case of Scotland in the international context. Medical Research Archives. 2017; 5 (3): 1-34

9. Cameron A, Ewen M, Ross-Degnan D, Ball D, Laing R. Medicine prices, availability, and affordability in 36 developing and middle-income countries: a secondary analysis. Lancet. 2009;373(9659):240-9.

10. HAI. Policy Options for Promoting the Use of Generic Medicines in Low and Middle-income Countries. March 2016. Available at URL: file:///C:/Users/mail/Downloads/HAl\%20GM\%202016.pdf 11. Kostic M, Djakovic L, Sujic R, Godman B, Jankovic SM. Inflammatory Bowel Diseases (Crohn $s$ Disease and Ulcerative Colitis): Cost of Treatment in Serbia and the Implications. Applied health economics and health policy. 2017;15(1):85-93.

12. Choudhry NK, Denberg TD, Qaseem A. Improving Adherence to Therapy and Clinical Outcomes While Containing Costs: Opportunities From the Greater Use of Generic Medications: Best Practice Advice From the Clinical Guidelines Committee of the American College of Physicians.

Annals of internal medicine. 2016;164(1):41-9.

13. Simoens S, Sinnaeve PR. Patient co-payment and adherence to statins: a review and case studies. Cardiovascular drugs and therapy. 2014;28(1):99-109.

14. Irazola VE, Gutierrez L, Bloomfield G, Carrillo-Larco RM, Dorairaj P, Gaziano T, et al. Hypertension Prevalence, Awareness, Treatment, and Control in Selected LMIC Communities: Results From the NHLBI/UHG Network of Centers of Excellence for Chronic Diseases. Global heart. 2016;11(1):47-59.

15. Cameron A, Mantel-Teeuwisse AK, Leufkens HG, Laing RO. Switching from originator brand medicines to generic equivalents in selected developing countries: how much could be saved? Value in health. 2012;15(5):664-73.

16. Hassali MA, Alrasheedy AA, McLachlan A, Nguyen TA, Al-Tamimi SK, Ibrahim MI, et al. The experiences of implementing generic medicine policy in eight countries: A review and recommendations for a successful promotion of generic medicine use. Saudi pharmaceutical journal. 2014;22(6):491-503.

17. Civaner M. Sale strategies of pharmaceutical companies in a "pharmerging" country: the problems will not improve if the gaps remain. Health policy. 2012;106(3):225-32. 
18. Novartis. Kenya first country to launch 'Novartis Access', expanding affordable treatment options against chronic diseases. Oct 15 2015. Available at URL:

https://www.novartis.com/news/media-releases/kenya-first-country-launch-novartis-accessexpanding-affordable-treatment

19. Novartis. Novartis access. Available at URL: https://www.novartis.com/about-us/corporateresponsibility/expanding-access-healthcare/novartis-access

20. Godman B, Shrank W, Wettermark B, Andersen M, Bishop I, Burkhardt T, et al. Use of Generics-A Critical Cost Containment Measure for All Healthcare Professionals in Europe?

Pharmaceuticals. 2010;3(8):2470-94.

21. Simoens S. A reviewof genericmedicine pricing in Europe. Generics and Biosimilar Journal. 2012;1(1):8-12.

22. Sermet C, Andrieu V, Godman B, Van Ganse E, Haycox A, Reynier JP. Ongoing pharmaceutical reforms in France: implications for key stakeholder groups. Applied health economics and health policy. 2010;8(1):7-24.

23. Dylst $P$, Vulto $A$, Simoens $S$. Analysis of French generic medicines retail market: why the use of generic medicines is limited. Expert review of pharmacoeconomics \& outcomes research. 2014;14(6):795-803.

24. Godman B, Sakshaug S, Berg C, Wettermark B, Haycox A. Combination of prescribing restrictions and policies to engineer low prices to reduce reimbursement costs. Expert review of pharmacoeconomics \& outcomes research. 2011;11(1):121-9.

25. Brkičić LS, Godman B, Bogut M, Sršen M, Kwon H-Y, de Bruyn W, Tabain T. Pharmaceutical pricing in Croatia: a comparison of ordinances in 2013 versus 2009 and their potential savings to provide future guidance. GaBI Journal. 2015;4(2):79-89.

26. Vogler $\mathrm{S}$. The impact of pharmaceutical pricing and reimbursement policies on generics uptake: implementation of policy options on generics in 29 European countries-an overview. Generics and Biosimilar Journal. 2012;1(2):93-100.

27. Simoens S. International comparison of generic medicine prices. Current medical research and opinion. 2007;23(11):2647-54.

28. Dylst $\mathrm{P}$, Simoens $\mathrm{S}$. Does the market share of generic medicines influence the price level?: a European analysis. PharmacoEconomics. 2011;29(10):875-82.

29. Garuoliene K, Godman B, Gulbinovic J, Wettermark B, Haycox A. European countries with small populations can obtain low prices for drugs: Lithuania as a case history. Expert review of pharmacoeconomics \& outcomes research. 2011;11(3):343-9.

30. Markovic-Pekovic V, Skrbic R, Godman B, Gustafsson LL. Ongoing initiatives in the Republic of Srpska to enhance prescribing efficiency: influence and future directions. Expert review of pharmacoeconomics \& outcomes research. 2012;12(5):661-71.

31. Nguyen TA HM, McLachlan A. Generic medicines policies in the Asia Pacific region: ways forward. WHO South-East Asia Journal of Public Health 2013;2(1):72-4.

32. Fadare JO, Adeoti AO, Desalu OO, Enwere OO, Makusidi AM, Ogunleye O, et al. The prescribing of generic medicines in Nigeria: knowledge, perceptions and attitudes of physicians. Expert review of pharmacoeconomics \& outcomes research. 2016;16(5):639-50.

33. Kumar R, Hassali MA, Saleem F, Alrasheedy AA, Kaur N, Wong ZY, et al. Knowledge and perceptions of physicians from private medical centres towards generic medicines: a nationwide survey from Malaysia. Journal of pharmaceutical policy and practice. 2015;8(1):11.

34. Hassali MA, Wong ZY, Alrasheedy AA, Saleem F, Mohamad Yahaya AH, Aljadhey H. Perspectives of physicians practicing in low and middle income countries towards generic medicines: a narrative review. Health policy . 2014;117(3):297-310.

35. Hassali MA, Thambyappa J, Saleem F, ul Haq N, Aljadhey H. Generic Substitution in Malaysia: Recommendations from a Systematic Review. Journal of Applied Pharmaceutical Science 2012;2(8):159-64.

36. Ofori-Asenso R, Brhlikova P, Pollock AM. Prescribing indicators at primary health care centers within the WHO African region: a systematic analysis (1995-2015). BMC public health. 2016;16:724.

37. Zeng W, Zhen J, Feng M, Campbell SM, Finlayson AE, Godman B. Analysis of the influence of recent reforms in China: cardiovascular and cerebrovascular medicines as a case history to provide future direction. Journal of comparative effectiveness research. 2014;3(4):371-86.

38. Kwon HY, Kim H, Godman B, Reich MR. The impact of South Korea's new drug-pricing policy on market competition among off-patent drugs. Expert review of pharmacoeconomics \& outcomes research. 2015;15(6):1007-14. 
39. Abuelkhair M, Abdu S, Godman B, Fahmy S, Malmstrom RE, Gustafsson LL. Imperative to consider multiple initiatives to maximize prescribing efficiency from generic availability: case history from Abu Dhabi. Expert review of pharmacoeconomics \& outcomes research. 2012;12(1):115-24.

40. Paris V. Belloni A. Value in Pharmaceutical Pricing. Available at URL: http://www.oecdilibrary.org/social-issues-migration-health/value-in-pharmaceutical-pricing 5k43jc9v6knx-en 41. Godman B, Ortwijn W, de Waure C, Mosca I, Puggina A, Specchia ML et al. Links between Pharmaceutical R\&D Models and Access to Affordable Medicines. A Study for the ENVI COMMITTEE. Available at URL: http://www.europarl.europa.eu/RegData/etudes/STUD/2016/587321/IPOL STU(2016)587321 EN.pdf

42. Faleiros DR, Alvares J, Almeida AM, de Araujo VE, Andrade El, Godman BB, et al. Budget impact analysis of medicines: updated systematic review and implications. Expert review of pharmacoeconomics \& outcomes research. 2016;16(2):257-66.

43. Simoens S, Picavet E, Dooms M, Cassiman D, Morel T. Cost-effectiveness assessment of orphan drugs: a scientific and political conundrum. Applied health economics and health policy. 2013;11(1):1-3.

44. Haycox A. Why Cancer? PharmacoEconomics. 2016;34(7):625-7.

45. Ferrario A, Kanavos P. Dealing with uncertainty and high prices of new medicines: a comparative analysis of the use of managed entry agreements in Belgium, England, the Netherlands and Sweden. Soc Sci Med. 2015;124:39-47.

46. Ferrario A, Kananvos P. Managed entry agreements for pharmaceuticals: the European experience. EMiNet, Brussels, Belgium. Available at URL: http://eprints.Ise.ac.uk/50513/2013 47. WHO. Access to new medicines in Europe: technical review of policy initiatives and opportunities for collaboration and research. Available at URL:

http://www.euro.who.int/ data/assets/pdf file/0008/306179/Access-new-medicines-TR-PIOcollaboration-research.pdf?ua $=1$

48. Godman B, Bucsics A, Burkhardt T, Haycox A, Seyfried H, Wieninger P. Insight into recent reforms and initiatives in Austria: implications for key stakeholders. Expert review of pharmacoeconomics \& outcomes research. 2008;8(4):357-71. 